\title{
Microgrid Test-Beds and Its Control Strategies
}

\author{
Manika Nakaththalage Suranjith Ariyasinghe, Kullappu Thantrige Manjula Udayanga Hemapala
}

Department of Electrical Engineering, University of Moratuwa, Katubedda, Sri Lanka.

Email: udayanga@elect.mrt.ac.lk

Received September $26^{\text {th }}$, 2012; revised October $26^{\text {th }}, 2012$; accepted November $3^{\text {rd }}, 2012$

\begin{abstract}
The scares of conventional energy resources and negative environmental impact of non renewable energy recourses are accelerating the technologies for new non conventional environment friendly energy options. Most of utility the grids are saturated with bulk energy resources but there are plenty of available small scale energy resources distributed around regions. Most of them are identified as wind, photo voltaic (PV), solar thermal and waste heat from industries and cooling tower of combined cycle power plants. It is difficult to gain full potential from these renewable energy resources as when they are connected to the power system individually, it leads to hindering the system stability. Microgrid is an attractive option to harness the benefits offered by distributed generation, eliminating constraints on high penetration of Distributed Energy Resources (DER). The microgrid provides an interface between central grid and micro devices to overcome these individual integration issues. So microgrid should capable to address those issues to optimize grid stability and power quality. Control system of the microgrid can be discriminated as voltage and frequency control, power flow balancing, load sharing, and protection as well as islanding and resynchronization. This research is focused on design and development of a microgrid test-bed for experimenting several kinds of microgrid topologies and coordination of individual components with a well defined energy management scheme.
\end{abstract}

Keywords: Microgrid; Distributed Generation; Renewable Energy

\section{Introduction}

The scares of conventional energy resources and negative environmental impact of non renewable energy recourses are accelerating the technologies for new non conventional environment friendly energy options. Most of the utility grids are saturated with bulk energy resources but there are plenty of available small scale energy resources distributed around region. Most of them are identified as wind, photo voltaic (PV), solar thermal and waste heat from industries and cooling tower of combined cycle power plants. It is difficult to gain full potential from these renewable energy resources as when they are connected to the power system individually, it leads to hindering the system stability. This is basically due to uncertainty, randomness, intermittent and uncontrollable nature of these resources $[1,2]$. The microgrid is a well defined option to ensure the benefits offered by distributed generation [35]. Microgrid is integrated with those distributed energy resources and it is appeared as a single bulk energy supply to the central grid at the point of common coupling.

\section{Overview of the Microgrid}

The microgrid is an emerging technology for enhancing the productivity of the existing power system in a region.
It is integrated with small scale distributed generators, distributed storages and variety of consumer loads [6-8]. Microgrid defers from central grid due to the decentralize control architecture and active behavior of the low voltage (LV) distribution system rather than passive behavior (see Figures 1(a) and (b)). Microgrid does not have DERs with the growth of demand for clean and environment friendly energy sources, the microgrid plays a key role by integrating collections of controllable micro sources and loads into the central power system. Microgrid is a power system operates autonomously which supply reliable and high quality electric power at the point of customer side.

Microgrids allow for generation technologies from a wide variety of primary energy sources, often they are renewable and waste energy forms along with storage devices such as Combined Heat and Power (CHP), Fuel Cells, Wind turbines, Solar PV and Microturbines. It also consist small internal combustion engines and micro hydros. Total capacity of a microgrid is not more than 10 MVA. Controlled loads are operating in an autonomous manner hopefully without necessity of real time communication. DERs are unlikely introduced several constraints when they are connected to the central grid [9]. Small number of grid connected DERs may not make conside- 
rable issue on the stability of the high-voltage transmission systems. However, if lots of DERs connected to the system then they could have a substantial influence on grid stability and power quality by affecting voltage and frequency control, irregular power flow pattern. This is because of uncontrollable nature of these resources [10].

Microgrid is an attractive option to harness the benefits offered by distributed generation, eliminating the constraints on high penetration of DER. The microgrid provides an interface between central grid and micro devices to overcome these individual integration issues. So microgrid should be capable to address those issues to optimize grid stability and power quality. Control system of the microgrid can be discriminated as voltage and frequency control, power flow balancing, load sharing, and protection as well as islanding and resynchronization.

Most of the unreliable components of a power system are appeared at distribution level. This is because of lack of technological upgrades at the distribution level. So in the case of development of microgrid, efficient use of distribution level resources may concern [11]. High penetration of DER is caused a structural change in the

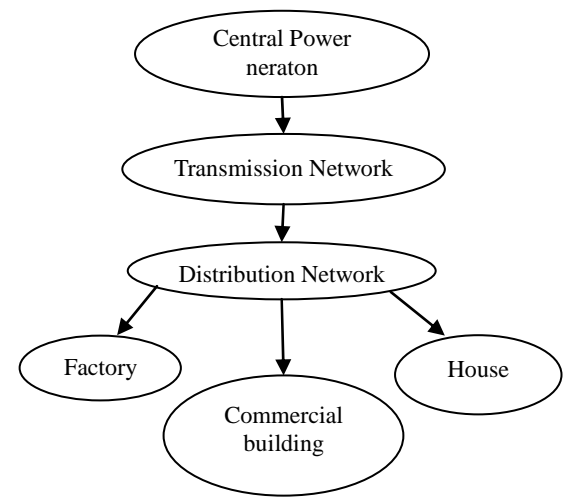

(a)

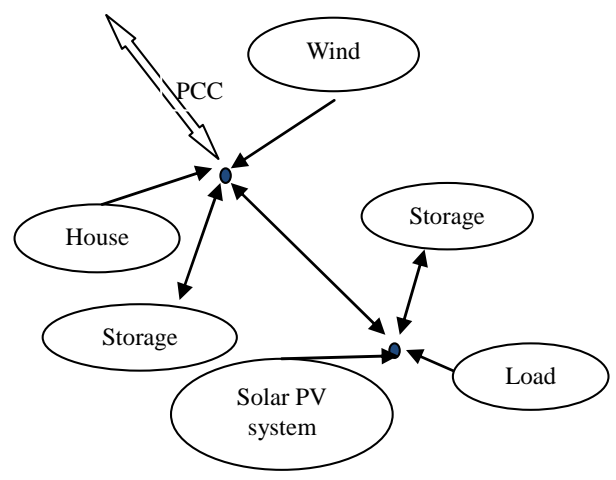

(b)

Figure 1. (a) Centralized behavior of the traditional power system; (b) Decentralized behavior of the modern power system. traditional centralized power system and it use high technologies at distribution level and power system architecture likely to be lay horizontally at the distribution level.

Design of a microgrid can be differentiated according to the applications and expectations. Some microgrids are developed to achieve high end use reliability and stability. Reliability is a common property for a microgrid. Microgrids are able to use more reliable and controllable energy sources like diesel sets, natural energy sources etc. to ensure reliability and stability of the system. Most of these types are implemented as a backup system for large industries and military stations located in remote areas. Some others will integrate more renewable and waste energy resources. Overcoming limitations introduced by these kinds of resources is a challenging task. It is seen that there is no clear common architecture for microgrids. So design, implementation and operation of a microgrid are differentiated according to the purpose.

Microgrids are facilitating to operate in grid connected mode as well as in islanded mode of operation [12,13]. For both modes of operation there should be an optimized way of integration of all individual components to ensure the functionality of the microgrid under dynamic conditions. During the islanded mode energy management is a key aspect for supply the power to critical loads. Energy Management schemes are introduced for that purpose. Design and development of Energy management schemes for microgrids are much complicated and interesting task nowadays in power and energy sector [14]. More Intelligent control scheme is ensured the much reliable power to the customer [15].

Energy storage elements in the microgrid supports for the power balance of the microgrid according to the load fluctuations and at transient behaviors of the system. Energy storage devices are necessary for a microgrid as all energy resources are non-dispatchable. Available energy storage options in the microgrid are batteries, fly-wheels and super-capacitors [16]. Other than those major storage elements such as electrolyzes can be used to alleviate the power fluctuation of the microgrids [17]. Electrolyzes are used to produce hydrogen from excess power and fuel cells are reproduced electrical energy from hydrogen. Among those devices, fly wheel can be used as a central storage system for the whole microgrid. Energy storage devices are responsible for [16];

- Insure the power balance in a microgrid at rapid load fluctuations and transients as DGs with their lower inertia lack the capability in fast responding to these disturbances.

- Provides ride through capability when there are dynamic variations in intermittent energy sources and allows the DGs to operate as dispatchable units.

- Provides the initial energy requirement for a seamless 
transition between grid-connected to islanded operation to microgrids.

Microgrids are basically served two kinds of loads; critical loads and non-critical loads. Critical loads are basically commercial and industrial loads and residential loads are categorized as non critical loads [18].

Microgrids are connected to the central grid at the distribution level. Traditional distribution systems are relying lower priority for deploying new technology than transmission and generation systems in centralized electricity systems. So distribution components were the more unreliable components in an electricity system. With the integration of distributed energy resources at the consumer level, distribution network is no longer act as a passive network. So we are moving from traditional unidirectional energy flow to a bidirectional energy flow system by integrating distributed resources [8]. Key benefits from the microgrid can point out as:

- Microgrid as a whole increase the overall system reliability.

- Increase overall efficiency limits by heat recovery (CHP).

- Utilization of energy efficient generation resources.

- Integration of renewable energy resources.

- Reduce the network losses.

- Defer the high investment costs required for the network upgrades.

- Reduce the central generation reserve requirements.

- Distributed Generators (DG) provide local voltage support.

Future and Present prospects for power utilization is to improve the percentage of renewable generations of the total generation mix. However microgrid is experienced several constraints such as reliability improvements are costly, restricted expansion of centralized system, load growth, conflicting policy objectives and connection of intermittent renewable. Therefore more research in these fields is needed. For this purpose a complete laboratory scale microgrid is needed and few are already implemented by several researchers [19]. Microgrid test bed is needed which can be used do research in most of the areas in microgrids. But there is no accepted benchmark test system for microgrid. Therefore this research is focused on design and development of a microgrid test-bed for experimenting several kinds of microgrid topologies and coordination of individual components with a well defined energy management scheme.

\section{Microgrid Test Beds}

There is no particular accepted benchmark for microgrids and its test systems. Research and developments are going at universities and research institutes around the world. CERT microgrid test bed is the dominant commercialized test system [20]. Several control strategies are suggested to microgrid operation in other various test systems implanted. Due to high intermittent behavior of distributed resources is introduced some limitations on each control strategies. This review is focused some selected microgrid test-beds currently implemented in several regions.

\subsection{CERTS Microgrid Test-Bed}

The CERTS microgrid test-bed is located at Columgus, ohio and it is operated by American Electric Power. It consists of three feeders and one of them is connected with two convertor based sources driven by Natural gas. Second feeder is powered by the same kind of source and other feeder is connected to the utility grid but it can also be powered by distributed generator when static switch is closed. Load banks and fault load points are implemented at each point along the feeders.

Communication is done by Ethernet connection in between Energy Management System (EMS) and at dynamic operation communication network is not used. So power sources are operated in distributed autonomous control with plug and play capabilities. There is no central controller implemented in CERT testbed.

Droop characteristics of each source are controlled by the real power vs frequency droop and the voltage is maintained using the reactive power vs voltage droop and providing the local stability insure there is no circulating reactive current between sources. The thyristor base static switch is used to control islanding conditions of the microgrid at any disturbance. IEEE P1547 Standard series say that distributed resources should be islanded at any disturbance of the system. In CERT microgrid that can be achieve through the static switch and then distributed resources are islanded and those are operated to serve local loads. Load bank at utility side from the static switch is operated by utility grid. Natural gas driven sources are fairly controllable than other sources like wind power and solar PV. Storage elements are more dominant when there is more intermittent energy sources are connected in to the system.

\subsection{UW Microgrid}

UW microgrid is designed to investigate the modeling and controlling issues in integrating the diesel generators into microgrids and also including convertor base sources [21]. The diesel generator is controlled by conventional mechanical governor to control droop of $3 \mathrm{~Hz}$ and voltage controller regulates the voltage. The new microgrid is being built into specialized high-bay lab space at the Wisconsin Energy Institute (WEI), which is slated for completion in early 2013. A facility that will obtain LEED certification, the WEI building features an open atrium that brings in natural light and serves as a meeting 
place for energy researchers from around the UW-Madison campus.

\subsection{The Residential Microgrid of Am Steinweg in Stutensee-German}

This microgrid system is connected to the medium voltage $(20 \mathrm{kV})$ network through a $400 \mathrm{kVA}$ transformer. Distributed energy sources used in this microgrid is CHP at $28 \mathrm{~kW}$ and PV systems at $35 \mathrm{~kW}$ and storages are battery bank with 880 Ah. $100 \mathrm{~kW}$ bidirectional inverters are used at battery banks to convert energy. The maximum power through the transformer is $150 \mathrm{~kW}$ [21].

After reviewing of several published research papers, Table 1 has formulated with the available microgrid test beds. According to the findings most of the test-beds are equipped with solar PV, Solar thermal, wind and CHP. But uses of micro or mini hydros are rare. Therefore the authors are specifically looking in that area as it is more important in countries like Sri Lanka. Sri Lanka has good potential of micro and mini hydro schemes which are currently serving for rural areas.

\section{Control Strategies for Microgrid Test-Beds}

Components of the distribution network at the microgrid should be included bidirectional power handling capabilities and intelligent control capabilities. In this context, distribution management system (DMS) should be included more advance applications and operations such as:

- Fast and automatic fault location, prediction, protec- tion and optimized interruptions capabilities.

- Dynamic and real time power flow analysis.

- Maintain voltage and var levels of optimal operation conditions according to the dynamic situations.

- Fast short circuit coordination analysis to ensure stability at transient conditions.

Control approaches are based on droop characteristics on each of individual devices in order to operate entire network in a stable manner during nominal operating conditions as well as during the transient conditions. There are hierarchical control levels used in modern microgrid (MG) technologies. Upper level of the MG is the MG central controller that provides the technical and economical management of the MG. Other levels of the MG are Load control (LC) and microsource control (MC). Almost all micro sources are connected to the system through power electronic interfaces and those are used to control the active and reactive power locally [22]. The load control is achieved by implementing load categories and controls the loads prior to these categories.

Microgrid has lower system inertia compared with conventional power systems due to lack of rotating masses. Controlling is much complicated during the transient situations. So there are additional fly wheels are used as energy storage devices to prevent that issue. Batteries or flywheels are used to provide energy balance during transient situations. Different types of control modes for inverter base control mechanisms can be categories as [23]:

- PQ control-the inverter is control to inject controlled active and reactive power to the system.

Table 1. Detailed overview of available microgrid test systems.

\begin{tabular}{|c|c|c|c|c|c|c|c|c|c|c|}
\hline \multirow{2}{*}{ Microgrid } & \multicolumn{7}{|c|}{ DGs } & \multicolumn{3}{|c|}{ Energy storage } \\
\hline & Solar PV & Solar thermal & Wind & Fuelcell & CHP & Hydro & $\begin{array}{c}\text { Diesel/ } \\
\text { steam/gas }\end{array}$ & Battery & Fly wheel & Capacitor \\
\hline $\begin{array}{l}\text { The CERTs } \\
\text { test-bed (US) }\end{array}$ & - & - & - & - & - & - & $3 \times 60 \mathrm{~kW}$ & Available & - & - \\
\hline $\begin{array}{c}\text { CESI } \\
\text { RICERCA } \\
\text { DER test } \\
\text { microgrid } \\
\text { (Italy) }\end{array}$ & $\begin{array}{c}34 \mathrm{~kW}(2 \times \\
10+14)\end{array}$ & $10 \mathrm{~kW}$ & $8 \mathrm{kVA}$ & - & $\begin{array}{c}110 \mathrm{~kW} \\
(100 \mathrm{~kW} \\
\text { micro turbine } \\
+10 \mathrm{~kW} \\
\text { Biomass })\end{array}$ & - & $7 \mathrm{kVA}$ & $\begin{array}{c}42 \mathrm{~kW}(2 \mathrm{hrs})+ \\
100 \mathrm{~kW}(1 \mathrm{hr})+ \\
64 \mathrm{~kW}(30 \mathrm{mins}) \\
+ \text { auxiliary }\end{array}$ & - & $150 \mathrm{kVAR}$ \\
\hline $\begin{array}{l}\text { The residential } \\
\text { microgrid of } \\
\text { Am steinweg in } \\
\text { stutendee } \\
\text { (German) }\end{array}$ & $35 \mathrm{kWp}$ & - & - & - & $28 \mathrm{~kW}$ & - & - & $100 \mathrm{~kW}(1 / 2 \mathrm{hrs})$ & - & - \\
\hline $\begin{array}{c}\text { Laboratory } \\
\text { scale microgrid } \\
\text { system at } \\
\text { NTUA } \\
\text { (Greece) }\end{array}$ & $\begin{array}{c}110 \mathrm{~W}+ \\
1.1 \mathrm{~kW}\end{array}$ & - & $1 \mathrm{~kW}$ & - & - & - & - & $4.5 \mathrm{~kW}(3 \mathrm{hrs})$ & - & - \\
\hline
\end{tabular}


- Droop control-droop control is referred to frequency regulation of the power system. Active power and frequency follow linear relationship as reactive power and system voltage. Frequency is deviated and cannot recover to its original level.

- V/f control-inverter behave as a voltage source that controls both magnitude and frequency of the voltage.

In single master operation, single V/f control is used as the reference voltage. All other inverters are operated in the PQ control mode and in the multi master operation there may be more than one inverters operated as VSI. At the islanded mode of operation the master controller should maintain the system frequency at desired level. Then master microsource will be operated at V/f control mode. When the system is change from islanded mode to grid connected mode, all the microsources can be operated at PQ control mode in order to achieve high level of output and efficiency.

Therefore the working mode of the master microsource is always to be transferred between V/f control mode and PQ control mode. Microgrid is leaved to undertake the unbalance power in the microgrid during grid connected operation. Microgrid would be better to acting as a constant load in order to reduce the difficulty of control.

When there is an immediate islanding situation all the microsources are transferred to the mode of droop control mode and leave them to share load demand according to their droop characteristics. During a planned islanding of a microgrid from utility grid, the power flow at the point of common coupling (PCC) should reduce and then disconnect it. Unplanned islanding may be occurred when there is a fault at the grid side or microgrid side or PCC bus voltage or system frequency is out of the connecting operation standard [24].

For managing the microgrid several other control techniques have introduced by several authors. Such as algorithms for group size estimation in communication, allocation of workers in embedded systems [25,26]. Some of the control strategies used by microgrid developers are summarized in Table 2 [27,28]. From the findings it is seen that multiagent system development is an emerging area of this scenario. Therefore authors are looking to use multiagent system for their control development.

\section{Proposed Microgrid Test System}

Proposed microgrid test-bed system (Figure 2) is focused on integration of emerging renewable sources and distributed control of individual sources, loads and other components to achieve higher reliability and power quality. It consists with a solar panel, wind plant simulator, battery storage unit, rotating machines, critical loads and non critical loads. In this design authors expect to ad- dress major constraints common to the microgrid system implementation such as load growth, connection of intermittent renewable, restricted expansion of centralized system and conflicting policy objectives. After proper calculations the components have selected by the authors for the proposed test-bed and the specifications of the selected items are given in Table 3.

Distributed autonomous criteria's could be applicable for the microgrid control strategies in order to ensure high performance and reliability of the microgrid systems. In this concern all distributed recourses have equal level of intelligence to take decision and predictions, those are supported to self controlling and send information to the other end devices to support to take decisions individually. Intelligent loads, generators, storage devices and point of common coupling (PCC) actively participate to achieve system stability and optimal level of operation. There is no any kind of central control or secondary level of control and all nodes of the system have equal level of contribution to take decision about operation state of the microgrid. Every nodes is taken their own decisions and every node is capable to process available data and

Table 2. Detailed overview of available control systems of microgrid test systems.

Microgrid
Boston bar.
(Canada)

Figure 2. Proposed microgrid test-bed. 
Table 3. Detailed selected components and specifications.

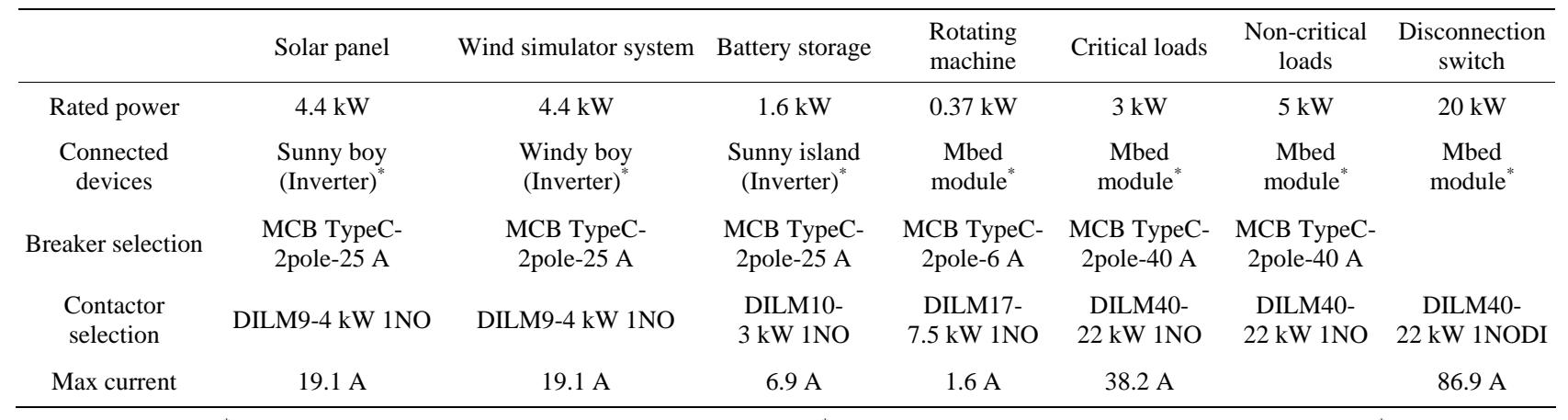

Sunny boy (Inverter) ${ }^{*}$ : Inverter system for solar PV system; Windy boy (Inverter) ${ }^{*}$ : Inverter system for wind power system; Mbed module*: Processor based device for control contactors.

communicate only the information rather than raw data.

All resources can be connected or disconnected in anytime with the microgrid in ad-hoc manner and it will not affect for the whole operation of the system. Individual devices has no idea about behavior of other devices and it knows only its own responsibilities and it is capable to send and receive information relevant to them.

\section{Conclusion}

Microgrid is a well known solution for power and energy preservation. Microgrid consists of decentralized control and distributed components at distribution level of the central grid. Individual components of the microgrid are intelligent to change their state to optimized system operation. Microgrids have impacts on national grid in many aspects. Transmission loss reduction, high service quality, reduction of demand for distribution and transmission facilities, support for rural electrification and generation redundancy are favorable features for the utility grid. At peak times, microgrids back up for demand reduction in utility grids by the ways of either reducing load or increasing generation. When faults occur in utility grid, islanding operation of microgrid is harmful for equipments and utility networks. Use of conventional protection schemes in situations like this would cause problems such as false tripping of feeders and protective devices, blind protection, unsynchronized reclosing, prevention of automatic reclosing, unwanted islanding etc. Hence special anti-islanding protection schemes shoul be used. In cost estimation and tariff decisions, special features and benefits for utility and consumers of microgrids have to be properly recognized and valued. Therefore separate tariff categories and legal regulations should be performed for microgrid usage. The compatibility of microgrids on Sri Lankan national grid should be compared with data of pilot projects conducted in other countries and technically analyzed. Rural areas in North and North-East provinces in Sri Lanka can be recognized as areas having potential and necessity for microgrid service.
The legal, economical and social feasibility for microgrids should be studied. The authors are willing to simulate these issues in the proposed microgrid test bed for finding a good solution for the energy crisis.

\section{Acknowledgements}

The authors gratefully acknowledge the support provided by the Sri Lankan National Science Foundation (Grant number: RG/2011/ESA/02).

\section{REFERENCES}

[1] M. Black, V. Silva and G. Strbac, "The Role of Storage in Integrating Wind Energy,” 2005 International Conference on Future Power Systems, Amsterdam, 18 November 2005, $6 \mathrm{p}$.

[2] P. Harsha and M. Dahlehr, "Optimal Sizing of Energy Storage for Efficient Integration of Renewable Energy,” 50th IEEE Conference on Decision and Control and European Control Conference (CDC-ECC), Orlando, 12-15 December 2011, pp. 5813-5819.

[3] T. Ackermann, G. Andersson and L. Söder, "Distributed Generation: A Definition,” Electric Power Systems Research, Vol. 57, No. 3, 2001, pp. 195-204.

[4] H. Zareipour, K. Bhattacharya and C. Canizares, "Distributed Generation: Current Status and Challenges,” 36th Annual North American Power Symposium (NAPS), Moscow, 9-10 August 2004.

[5] G. Pepermans, J. Driesen, D. Haeseldonckx, R. Belmans and W. D’haeseleer, "Distributed Generation: Definition, Benefits and Issues,” Energy Policy, Vol. 33, No. 6, 2005, pp. 787-798.

[6] J. Driesen and J. Katiraei, "Design for Distributed Energy Resources,” Power and Energy Magazine, Vol. 6, No. 3, 2008, pp. 30-40. doi:10.1109/MPE.2008.918703

[7] R. H. Lasseter and P. Paigi, "Microgrid: A Conceptual Solution,” IEEE 35th Annual Power Electronics Specialists Conference, 20-25 June 2004, Vol. 6, pp. 4285-4290.

[8] R. H. Lasseter, "Microgrid and Distributed Generation," Journal of Energy Engineering, Vol. 133, No. 3, 2007, pp. 144-149. 
doi:10.1061/(ASCE)0733-9402(2007)133:3(144)

[9] K. Rudion, A. Orths, Z. A. Styczynski and K. Strunz, "Design of Benchmark of Medium Voltage Distribution Network for Investigation of DG Integration,” 2006 IEEE Power Engineering Society General Meeting, Montreal, 16 October 2006, p. 6.

[10] H. Nikkhajoei and R. H. Lasseter, "Distributed Generation Interface to the CERTS Microgrid," IEEE Transactions on Power Delivery, Vol. 24, No. 3, 2009, pp. 15981608. doi:10.1109/TPWRD.2009.2021040

[11] B. Kroposki, C. Pink, T. Basso and R. DeBlasio, "Microgrid Standards and Technology Development," Power Engineering Society General Meeting, 24-28 June 2007, Tampa, pp. 1-4.

[12] S. Niklas, "Islanding Detection in Power Systems," Licentiate Thesis, Department of Industrial Electrical and Automation, Lund University, Lund, 2005.

[13] S. P. Chowdhury, C. F. Ten and P. A. Crossley, "Islanding Protection of Distribution Systems with Distributed Generation-A Comprehensive Survey Report,” 2008 IEEE Power and Energy Society General MeetingConversion and Delivery of Electrical Energy in the 21st Century, Pittsburgh, 20-24 July 2008, pp. 1-8.

[14] C. Sudipta, D. Manoja and M. G. Simoes, "Distributed Intelligent Energy Management System for a Single-Phase High-Frequency AC Microgrid,” IEEE Transactions on Industrial Electronics, Vol. 54, No. 1, 2007, pp. 97-109. doi:10.1109/TIE.2006.888766

[15] S. J. Chatzivasiliadis, N. D. Hatziargyriou and A. L. Dimeas, "Development of an Agent Based Intelligent Control System for Microgrids," Power and Energy Society General Meeting-Conversion and Delivery of Electrical Energy in the 21st Century, Pittsburgh, 20-24 July 2008, pp. 1-6.

[16] D. K. Nichols, J. Stevens, R. H. Lasseter and H. T. Vollkommer, "Validation of the CERTS Microgrid Concept the CEC/CERTS Microgrid Testbed,” Power Engineering Society General Meeting, Quebec, 2006.

[17] X. J. Li, D. Hui, X. K. Lai and T. Yan, "Power Quality Control in Wind/Fuel Cell/Battery/Hydrogen Electrolyzer Hybrid Microgrid Power System,” In: O. Ivanov, Ed., Applications and Experiences of Quality Control, InTech, Vienna, 2011, pp. 579-594.

[18] M. Pipattanasomporn, H. Feroze and S. Rahman, "MultiAgent Systems in a Distributed Smart Grid: Design and Implementation," Power Systems Conference and Expo- sition, Seattle, 15-18 March 2009, pp. 1-8.

[19] Z. G. Yang, "Construction, Operation and Control of a Laboratory-Scale Microgrid,” 3rd International Conference on Power Electronics Systems and Applications, Nanjing, 20-22 May 2009, pp. 1-5.

[20] S. Krishnamurthy, T. M. Jahns and R. H. Lasseter, "The Operation of Diesel Gensets in a CERTS Microgrid," IEEE PES General Meeting-Conversion and Delivery of Electrical Energy, Chicago, 2008. pp. 1-8.

[21] N. W. A. Lidula and A. D. Rajpakshe, "Microgrids Research: A Review of Experimental Microgrids and Test Systems," Renewable and Sustainable Energy Reviews, Vol. 15, No. 1, 2011, pp. 186-202. doi:10.1016/j.rser.2010.09.041

[22] J. A. P. Lopes, C. L. Moreira, A. G. Madureira, F. O. Resende, X. Wu, N. Jayawarna, Y. Zhang, N. Jenkins, F. Kanellos and N. Hatziargyriou, "Control Strategies for Microgrids Emergency Operation,” 2005 International Conference on Future Power Systems, Amsterdam, 18 November 2005, p. 6.

[23] K. De Brabandere, K. Vanthournout, J. Driesen, G. Deconinck and R. Belmans, "Control of Microgrids," Power Engineering Society General Meeting, Tampa, 24-28 June 2007, pp. 1-7.

[24] S. S. Venkata, R. W. Uluski and M. McGranaghan, “Critical Elements [Guest Editorial],” Power and Energy Magazine, Vol. 9, No. 5, 2011, pp. 12-20. doi:10.1109/MPE.2011.941872

[25] M. Brambilla, C. Pinciroli, M. Birattari and M. Dorigo, "A Reliable Distributed Algorithm for Group Size Estimation with Minimal Communication Requirements," ICAR 2009, Munich, 22-26 June 2009, pp. 1-6.

[26] W. Agassounon, A. Martinoli and R. Goodman, "A Scalable, Distributed Algorithm for Allocating Workers in Embedded Systems," 2001 IEEE International Conference on Systems, Man, and Cybernetics, Piscataway, Vol. 5, 2001, pp. 3367-3373.

[27] X. Wei, X. B. Tan and J. S. Baras, "A Hybrid Scheme for Distributed Control of Autonomous Swarms," Proceedings of the 2005 American Control Conference, 8-10 June 2005, Vol. 5, pp. 3486-3491.

[28] N. R. Hoff, A. Sagoff, R. J. Wood and R. Nagpal, “Two Foraging Algorithms for Robot Swarms Using Only Local Communication," 2010 IEEE International Conference on Robotics and Biomimetics (ROBIO), Tianjin, 1418 December 2010, pp. 123-130. 